\title{
Modular Synthesis of Fischer Biscarbene Complexes of Chromium
}

\author{
Hana Váňová, ${ }^{\dagger}$ Tomáš Tobrman, ${ }^{\dagger}$ Irena Hoskovcová ${ }^{\ddagger}$ and Dalimil Dvořák ${ }^{\dagger^{*}}$. \\ ${ }^{\dagger}$ Department of Organic Chemistry, University of Chemistry and Technology, Prague, Technická 5, 16628 \\ Prague 6, Czech Republic \\ ${ }^{\dagger}$ Department of Inorganic Chemistry, University of Chemistry and Technology, Prague, Technická 5, 16628 \\ Prague 6, Czech Republic
}

Supporting information - polarograms of the carbene complexes 1a, 3a, 4a, 6d and 9

The original plotter curves were digitized using WebPlotDigitizer, Version 3.9, October 2015, by Ankit Rohatgi, website http://arohatgi.info/WebPlotDigitizer, achieved August $1^{\text {st }} 2016$. 

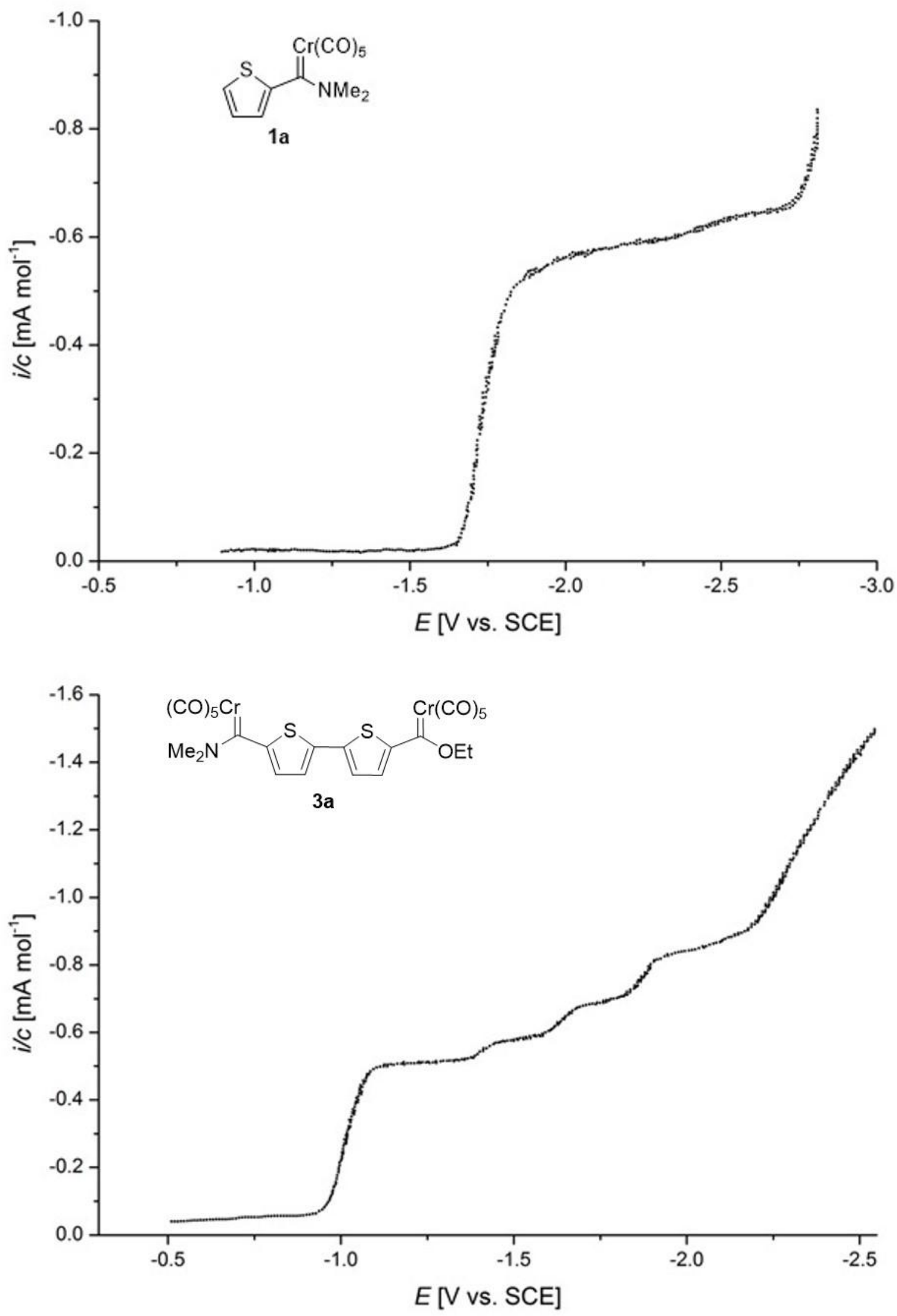




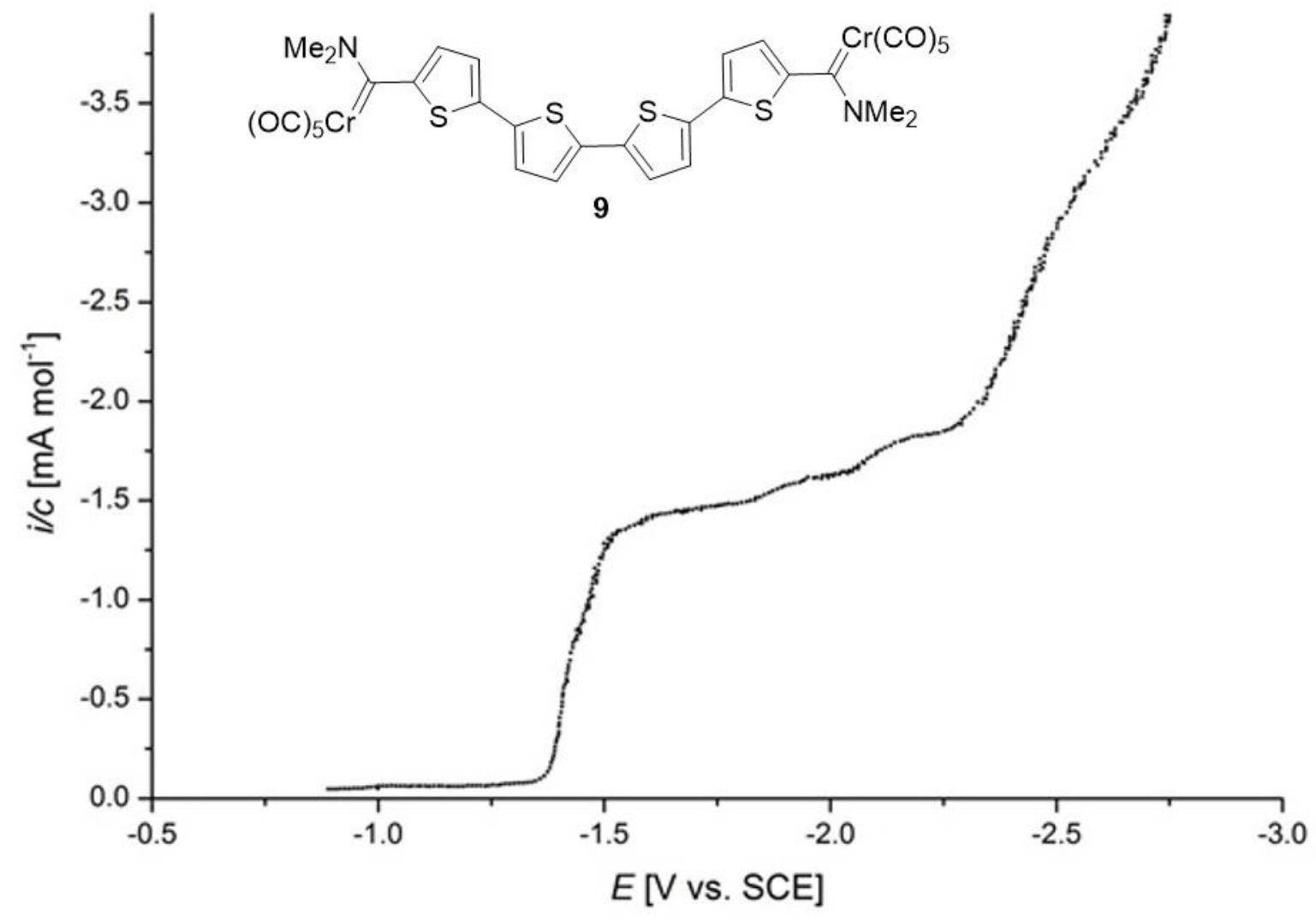

